\title{
Effect of Pharmacological Treatment for Attention-Deficit Hyperactivity Disorder on Motor Coordination: Open Label Study
}

\author{
Kee Jeong Park', Kukju Kweon', Saejeong Lee', \\ Yun Shin Lim', Yoo Sook Joung ${ }^{2}$, and Hyo-Won Kim \\ ${ }^{1}$ Department of Psychiatry, University of Ulsan College of Medicine, Asan Medical Center, Seoul, Korea \\ ${ }^{2}$ Department of Psychiatry, Sungkyunkwan University School of Medicine, Samsung Medical Center, Seoul, Korea
}

\section{주의력결핍 과잉행동장애 아동의 약물치료가 운동협응력에 미치는 효과: 개방연구}

박기정 ${ }^{1}$, 권국주 $^{1}$, 이세정 ${ }^{1}$, 임연신 ${ }^{1}$, 정유숙 $^{2}$, 김효원 $^{1}$

울산대학교 의과대학 서울아산병원 정신건강의학교실, ${ }^{1}$ 성균관대학교 의과대학 삼성서울병원 정신건강의학교실

Objectives: The objective of this study was to investigate the effect of pharmacological treatments for attention-deficit hyperactivity disorder (ADHD) on motor coordination, using the Developmental Coordination Disorder Questionnaire (DCDQ).

Methods: The participants were recruited from April 2015 to November 2016 from the Department of Psychiatry of Asan Medical Center and were treated for 3 months with methylphenidate or atomoxetine. The illness severity at baseline and 3 months were scored using the ADHD Rating Scale (ARS), Clinical Global Impression-Severity Scale (CGI-S) and/or Clinical Global Impression-Improvement Scale (CGI-I). A total of 39 children with ADHD (age 8.0 1.4 years, 36 boys) completed the Advanced Test of Attention (ATA) and their parents completed the DCDQ at baseline and 3 months. The paired t-test, mixed between-within analysis of variance and correlation analysis were used.

Results: The CGI-S ( $\mathrm{p}<0.001)$, ARS ( $\mathrm{p}<0.001)$, and fine motor/hand writing ( $\mathrm{p}=0.005)$ on the DCDQ were significantly changed between pre-treatment and post-treatment. When the participants were divided into those who were suspected of having developmental coordination disorder (DCD) $(n=23)$ and those who probably did not $(n=16)$, the control during movement, fine motor/hand writing and general coordination scores on the DCDQ showed the main effects for group ( $<<0.001, p<0.001$ and $p<0.001$, respectively). The fine motor/hand writing on the DCDQ has a significant main effect for time $\left[\mathrm{F}(1,37)=7.31, \mathrm{p}=0.010, \eta^{2}=0.405\right]$ and the interaction effect between group and time was also significant $\left[\mathrm{F}(1,37)=4.63, \mathrm{p}=0.038, \eta^{2}=0.111\right]$. The baseline visual commission error on the ATA is significantly correlated with the changes in the DCDQ total scores $(\mathrm{r}=0.330, \mathrm{p}=0.040)$.

Conclusion: Our results provide preliminary evidence that pharmacological treatment for ADHD improves not only the core symptoms of ADHD, but also the motor coordination. Further studies are needed to confirm the effect of the pharmacological treatment for ADHD on the motor coordination.

Key Words: Children; Attention-deficit hyperactivity disorder; Pharmacotherapy; Developmental coordination.

Received: December 27, 2016 / Revision: March 1, 2017 / Accepted: August 16, 2017

Address for correspondence: Hyo-Won Kim, Department of Psychiatry, University of Ulsan College of Medicine, Asan Medical Center, 88 Olympic-ro 43gil, Songpa-gu, Seoul 05505, Korea

Tel: +82-2-3010-3414, Fax: +82-2-485-8381, E-mail: shingubi@amc.seoul.kr

서 론

주의력결핍 과잉행동장애(attention-deficit hyperactivity

This is an Open Access article distributed under the terms of the Creative Commons Attribution Non-Commercial License (http://creativecommons.org/licenses/by-nc/4.0) which permits unrestricted non-commercial use, distribution, and reproduction in any medium, provided the original work is properly cited. disorder, ADHD)는 학령기 아동에서 가장 흔한 정신과적 질환 으로 유병률은 5 8\%로 알려져 있다. ${ }^{1)}$ 주의력결핍, 과잉행동, 충동성이 핵심적 특징이며,2) 이는 행동문제, 학업수행 및 직업 적 성취 저하로까지 이어진다.)

$\mathrm{ADHD}$ 아동은 신체균형, 이동운동(locomotor) 등의 대근육 운동뿐만 아니락) 글씨쓰기와 같은 소근육 운동도 정상아동 
에 비해 성취수준이 유의하게 낮은 것으로 알려져 있다. ${ }^{3,4}$ 또 한 $\mathrm{ADHD}$ 와 운동협응력의 저하가 동반된 아동에서 우울장 애, 불안장애 등의 공존질환이 더 흔한 것으로 보고된다. ${ }^{5}$ $\mathrm{ADHD}$ 로 인한 자존감 손상과 더불어 운동협응력 저하 때문 에 또래 스포츠 활동에서 배제 당하는 부정적 경험 등이 내재 화 장애의 발현에 영향을 주는 것으로 생각된다. 나아가 $\mathrm{ADHD}$ 와 발달성 협응장애(developmental coordination disorder, $\mathrm{DCD}$ )가 공존하는 경우도 많은데, 기존 연구들은 $\mathrm{ADHD}$ 와 $\mathrm{DCD}$ 의 공존율을 $50 \%$ 가까이 보고한다.) $\mathrm{ADHD}$ 와 $\mathrm{DCD}$ 가 공존하는 아동은 $\mathrm{ADHD}$ 단독일 때보다 동작성 지능이 낮고, 내재화 증상이 더 많다고 보고된다. ${ }^{8}$ 아울러 이들은 성인이 된 이후에도 $\mathrm{ADHD}$ 증상이 더 많이 남으며, 반사회성 인격장애, 알코올 중독 및 읽기 장애 등의 질환빈도가 더 높고, 낮은 교 육수준의 빈도가 더 높은 등 예후가 나쁘다고 알려져 있다.9) 또한 이 경우에는 메칠페니데이트 등의 약물치료뿐만 아니라 작업치료, 물리치료 등 운동협응력 향상을 위한 추가적 치료 가 함께 필요하다고 알려져 있다. ${ }^{10}$ 그렇기 때문에 $\mathrm{ADHD}$ 아동 에서 조기에 운동협응력 수준을 평가하고, 적극적으로 치료 하는 것이 중요하다.

$\mathrm{ADHD}$ 의 약물치료가 $\mathrm{ADHD}$ 의 핵심적 특징인 주의력결핍 및 과잉행동 등에 미치는 영향에 대해서는 다수의 연구에서 잘 밝혀져 있는데 비해, ${ }^{11)} \mathrm{ADHD}$ 의 약물치료가 운동능력의 저하 에 끼치는 효과에 대한 연구들은 적은 편이다. $\mathrm{ADHD}$ 의 약물 치료가 운동능력의 저하에 미치는 영향을 살펴본 기존 연구에 서는, 약물치료가 자세안정성(postural stability) ${ }^{12}$ 과 균형, ${ }^{13)}$ 소 근육 운동기능 ${ }^{14-16)}$ 을 호전시킴을 보고하였다. 그러나 이들 연 구는 대부분 일회성 또는 단기간의 투약이 운동기능에 미치 는 영향을 다루었으며, 4주 이상의 약물치료가 운동기능에 미 치는 영향을 평가하거나, $\mathrm{ADHD}$ 증상과 운동기능의 호전이 어떻게 관련되는지 확인한 연구는 드물었다. 따라서 본 연구에 서는 $\mathrm{ADHD}$ 약물치료 전후의 운동협응력을 비교하여 3개월간 의 약물치료가 $\mathrm{ADHD}$ 아동의 운동협응력에 미치는 효과를 확 인하고 이러한 운동협응력의 변화가 $\mathrm{ADHD}$ 증상의 변화와 어 떻게 연관되는지 살펴보고자 하였다.

\section{방 법}

\section{대 상}

연구대상자는 2015년 4월부터 2016년 11월까지 서울아산병 원 소아청소년 정신건강의학과에 내원한 아동 가운데 1) 만 5 12세, 2) Diagnostic and Statistical Manual of Mental Disorders-fourth edition(DSM-IV) 진단기준과 Kiddie-Schedule for Affective Disorders and Schizophrenia-Present and Life- time Version(K-SADS-PL)에 의하여 ADHD로 진단되었으며 약물치료가 필요하다고 판단되는 경우로 정했다. 그리고 다음 중 한 가지 이상의 경우에 해당하면 제외하였다: 1) 학습장애, 정신지체, 양극성 장애, 정신병장애, 발달장애, 기질성 뇌질환, 뇌전증, 신경과적 질환 등을 않고 있는 경우, 2) 약물치료가 필 요한 틱장애, 강박장애, 주요 우울장애 또는 불안장애를 가진 경우, 3) 심각한 자살사고가 있는 경우, 4) 최근 6개월 이내에 메 칠페니데이트 또는 아토목세틴 투여경험이 있는 경우, 5) 현재 심각한 의학적 상태(예: 심혈관계, 간, 신장, 호흡기계 질환, 녹 내장)에 있는 경우, 6) 알파-2 아드레날린 수용체 작용제, 항우 울제, 항정신병 약물, 벤조디아제핀, 항경련제를 현재 복용 중 이거나 중추신경계활동에 영향을 줄 수 있는 건강보조식품을 복용하고 있는 경우.

연구대상자에게는 약물치료 시작 전에 Developmental Coordination Disorder Questionnaire(DCDQ), ADHD Rating Scale(ARS), Advanced Test of Attention(ATA) 및 Clinical Global Impression-Improvement/Severity Scale(CGI-I/S)이 시행되었다. 이후 3개월간 메칠페니데이트 또는 아토목세틴으 로 표준 용량의 약물치료를 시행하였으며, 3개월 시점에서 상 기 검사들을 재시행하였다.

메칠페니데이트와 아토목세틴 표준 용량의 약물치료는 아 래 지침을 따라 시행되었으며, 임상의의 일상적 진료상 판단에 따라 약물의 종류를 정했다. 다만, 틱장애의 병력이 있거나 불 안장애가 동반된 경우에는 아토목세틴을 우선적으로 고려하 였다. 메칠페니데이트의 초회 용량은 체중 $30 \mathrm{~kg}$ 미만인 경우 methylphenidate-Osmotic controlled Release Oral delivery System(MPH-OROS, Concerta $\left.{ }^{\circledR}\right) 18 \mathrm{mg} /$ 일 또는 methylphenidate-Controlled Delivery(MPH-CD, Metadate $\mathrm{CD}^{\circledR}$ ) 10 $20 \mathrm{mg} /$ 일 또는 methylphenidate-Modified Release(MPH$\mathrm{MR}$, Medikinet ${ }^{\circledR}$ Retard) $5 \sim 10 \mathrm{mg} /$ 일, $30 \mathrm{~kg}$ 이상인 경우 $\mathrm{MPH}-\mathrm{OROS}$ 18 27 mg/일 또는 MPH-CD 10 20 mg/일 또 는 MPH-MR 5 10 mg/일로 권장하였다. 증량은 치료효과와 내약성에 따라 최대 60 72 mg/day 또는 $1.4 \mathrm{mg} / \mathrm{kg} /$ day까지 이루어지도록 하였다. 아토목세틴(Strattera $\left.{ }^{\circledR}\right)$ 의 초회 용량은 $0.5 \mathrm{mg} / \mathrm{kg} /$ 일, 최대 용량은 $1.4 \mathrm{mg} / \mathrm{kg} /$ 일로 권장하였다. 메칠 페니데이트 또는 아토목세틴의 약물 용량 변경은 1주일 이상 의 단위로 이루어지도록 했다.

본 연구는 서울아산병원 임상연구심의위원회의 승인을 얻 었으며 연구의 전 과정에 대해서 모든 연구대상자 및 그 보호 자로부터 서면동의를 얻었다(IRB No. 2014-0157). 


\section{평가도구}

Kiddie-Schedule for Affective Disorders and SchizophreniaPresent and Lifetime Version(K-SADS-PL)

32 개의 DSM-IV 소아청소년 정신과 질환의 현재 및 평생 이 환 상태를 평가할 수 있도록 고안된 반구조화된 면담도구인 K-SADS-PL은 개발자에 의해 신뢰도와 타당도가 검증되어 있다. ${ }^{17)}$ 한국판 K-SADS-PL은 Kim 등 ${ }^{18}$ 에 의해 번역되어 주 의력결핍 과잉행동장애(ADHD), 틱장애(tic disorder), 반항적 도전 장애(oppositional defiant disorder, ODD) 및 우울장애, 불안장애에 대해서 신뢰도와 타당도가 연구되었다. 도구 사용 경험이 풍부하고 면담에 익숙한 소아정신과 전문의 및 임상 심리정문가가 대상 아동과 부모에게 시행하였다.

\section{Developmental Coordination Disorder Questionnaire(DCDQ)}

$\mathrm{DCDQ}$ 는 Wilson 등 ${ }^{19}$ 이 발달성협응장애를 1차적으로 선별 하기 위한 도구로 개발한 5 15세 아동청소년용 행동평가척도 이다. 보호자가 아동의 일상생활 중 협응 정도를 평가하며, 소 요시간이 10분 내외로 짧아 간단하게 시행할 수 있다. 이 설문지 는 1) Control during movement, 2) Fine motor/hand writing, 3) General coordination 세 개의 하위척도로 구성되어 있다. 각 하위척도와 관련된 15 개 문항을 5 점 척도로 측정한다. 15 개 문항의 합산점수로 $\mathrm{DCD}$ 가능성을 평가하며, 총점은 15 점에 서 75점까지다. 이 척도에서는 문제가 많을수록 점수가 낮게 평 가되는데, 5 7세 아동은 46점 이하, 8 9세 아동은 55점 이하, 10 15세 아동은 57점 이하에서 $\mathrm{DCD}$ 의심군으로 분류된다. $\mathrm{DCDQ}$ 는 기존 연구 ${ }^{20}$ 를 통해 높은 내적 일치도 $(\alpha=0.94)$ 와 구 성타당도 $(\mathrm{p}<0.001)$ 가 증명되어 있으나, 현재까지 한국어판의 표준화 작업은 완전히 이루어지지 않았다.

\section{ADHD Rating Scale(ARS)}

$\mathrm{ADHD}$ 평가 척도(ADHD Rating Scale)는 $\mathrm{DuPaul}{ }^{21)}$ 이 학령 기 아동의 $\mathrm{ADHD}$ 증상을 평가하기 위해 개발한 아동용 행동 평가 척도다. 연구자, 부모, 교사가 각각 평가할 수 있도록 제작 되었다. 이 척도의 타당도와 신뢰도는 여러 연구에서 증명되었 으며, 국내에서는 So 등 ${ }^{22}$ 이 국내 아동 1044명을 대상으로 한 국어판 부모, 교사 $\mathrm{ADHD}$ 평가 척도의 타당도와 신뢰도를 증 명하였다.

\section{Advanced Test of Attention(ATA)}

정밀주의집중력검사는 주의력 평가 시 사용하는 전산화된 연속수행검사의 일종이다. 주의집중 및 충동조절 능력을 정 량적으로 측정할 수 있는 도구로 국내에서는 Shin 등리에 의
해 표준화가 이루어졌다.

정밀주의집중력검사는 시각, 청각 두 가지 소검사로 구성되 며, 각각의 소검사마다 누락오류(omission errors), 오경보 오 류(commission errors), 반응시간 평균(mean response time), 반응시간 표준 편차(standard deviation of reaction time; response time variability) 등의 4 가지 지표가 산출된다. 본 연 구에서는 $\mathrm{z}$ 점수를 사용했으며, 1.5 이상이면 정상범위를 벗 어나는 것으로 1.0 이상 1.5 미만인 경우 경계선으로 평가했다. 정밀주의집중력검사의 내적 일치도 계수는 0.87 이다.

Clinical Global Impression-Improvement/Severity Scale(CGII/S)

$\mathrm{CGI}-\mathrm{I} / \mathrm{S}$ 는 $\mathrm{Guy}^{24)}$ 가 개발한 관찰자 평가척도다. 질환의 심각 도와 치료에 대한 반응, 경과를 기술할 때 사용되며, 쉽고 빠 르게 정신건강의학과 질환을 평가할 수 있어 임상연구에 널 리 쓰인다. 임상질환에 대한 충분한 이해를 갖춘 평가자가 사 용할 경우 충분한 타당도가 있음이 여러 연구에서 밝혀진 바 있다. CGI-I는 질환의 호전도를 1점(very much improved)에 서부터 7점(very much worse)까지 평가하도록 구성되며, CGI-S 는 질환의 현재 중증도를 1점(normal)에서부터 7점(extremely ill)까지 평가하도록 구성되어 있다.

\section{자료분석}

치료 전후의 임상변수 비교 시에는 대응표본 $\mathrm{T}$ 검정(paired t-test)을 사용했고, 이후의 다중비교 보정에서는 Bonferonni 교정을 사용하였다. $\mathrm{DCD}$ 의심군과 비의심군에서의 치료 전후 $\mathrm{DCDQ}$ 값 비교 시에는 혼합설계 분산분석(mixed betweenwithin analysis of variance)을 사용하였다. DCDQ와 ADHD 관련 임상척도들과의 상관관계는 상관분석(correlation analysis)을 사용하여 분석하였다. 통계 프로그램으로는 Window 용 SPSS ver. 20(IBM Corp., Armonk, NY, USA)을 사용하였 고 유의수준은 $\mathrm{p}<0.05$ 로 정하였다.

\section{결 과}

본 연구에는 총 49명이 모집되었으나 10명이 중도 탈락하여, 최종적으로 분석에 포함된 연구대상자는 39 명이었다. 중도탈 락의 사유는 $\mathrm{ADHD}$ 약물 부작용(3명), 방문 거부(2명), 투약 거 부(2명), 항정신병 약물 사용(2명), 동의 철회(1명)였다.

중도탈락자 $(n=10)$ 와 최종 분석 포함대상자 $(n=39)$ 간의 인구 학적 특성 비교 시 연령 $(\mathrm{p}=0.115)$, 성별 $(\mathrm{p}=0.267)$, intelligence quotient(IQ, $\mathrm{p}=0.091), \mathrm{ADHD}$ 아형( $\mathrm{p}=0.087$ ) 및 공존질환(적 대적 반항장애, $\mathrm{p}=1.000$; 틱장애, $\mathrm{p}=0.569$; 유뇨증, $\mathrm{p}=0.370$; 특 
정공포증, $\mathrm{p}=0.370)$ 모두 유의한 차이가 없었다.

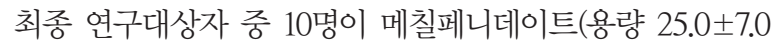
$\mathrm{mg}$ )로 치료받았고, 나머지 29명은 아토목세틴(용량 29.2 \pm 11.0 $\mathrm{mg}$ )으로 치료받았다. 전체 약물치료의 기간은 $91.7 \pm 16.5$ 일이 었고, 사용한 약물의 종류에 따른 기간은 메칠페니데이트를 사용한 아동에서 89.2 \pm 17.2 일, 아토목세틴을 사용한 아동에 서 $99.0 \pm 12.1$ 일로 그 통계적 차이는 유의하지 않았다 $(\mathrm{p}=0.107)$.

Table 1. Subjects characteristics

\begin{tabular}{lc}
\hline & Subjects $(\mathrm{n}=39)$ \\
\hline Age, years, mean (SD) & $8.0(1.4)$ \\
Gender, boys, n (\%) & $36(92.3)$ \\
IQ, mean (SD) & $93.4(12.7)$ \\
ADHD subtype, n (\%) & \\
Inattentive & $14(35.9)$ \\
Combined & $25(64.1)$ \\
Comorbid diagnosis, $\mathrm{n}(\%)$ & \\
ODD & $7(17.9)$ \\
Tic disorder & $5(12.8)$ \\
Enuresis & $1(2.6)$ \\
Specific phobia & $1(2.6)$ \\
\hline ADHD: attention-deficit hyperactivity disorder, $1 \mathrm{Q}:$ intelligent \\
quotient, NOS: not otherwise specified, ODD: oppositional defi- \\
ant disorder, SD: standard deviation
\end{tabular}

연구 중 치료약물의 종류가 변경되는 경우는 관찰되지 않았다.

또한 연구기간 중 전체 아동의 $38.5 \%$ (15명)에서 비약물적 치 료가 동반되었다. 시행된 비약물적 치료의 종류는 다음과 같았 다; 사회성 훈련(10명, 66.7\%), 놀이치료(6명, 40.0\%), 미술치료 (4명, 26.7\%)와 언어치료(3명, 20.0\%). 이들 중 사회성 훈련과 놀 이치료를 함께 하는 아동이 3명(20.0\%), 놀이치료와 언어치료 를 함께 하는 아동이 2명(13.3\%), 사회성 훈련과 미술치료를 함 께 하는 아동이 1명(6.7\%), 그리고 사회성 훈련, 언어치료, 미술 치료 셋을 모두 하는 아동이 1명(6.7\%) 있었다.

\section{인구학적 특성(Table 1)}

본 연구에서 최종분석에 포함된 39명의 $\mathrm{ADHD}$ 아동(연령 8.0 \pm 1.4 세)은 남아 36 명, 여아 3명으로 남아의 비율이 높았다. IQ 는 평균 $93.4 \pm 12.7$ 에 해당하였다. $\mathrm{ADHD}$ 의 아형은 주의력결핍 우세형이 14명(35.9\%), 혼합형이 25명(64.1\%)이었다. 공존질환 은 7명(17.9\%)에서 적대적 반항장애, 5명(12.8\%)에서 틱장애, 1 명 $(2.6 \%)$ 에서 유뇨증, 1 명(2.6\%)에서 특정 공포증이 관찰되었다.

약물치료 전후에 시행된 임상평가척도의 결과 비교(Table 2)

약물치료 전후에 시행된 CGI-S(p<0.001)와 ARS의 부주의 성 $(\mathrm{p}<0.001)$ 및 과잉행동-충동성 하위척도 $(\mathrm{p}<0.001)$ 는 치료

Table 2. Comparisons of measures between pre-treatment and post-treatment

\begin{tabular}{|c|c|c|c|c|c|c|}
\hline & \multicolumn{6}{|c|}{ Participants $(n=39)$} \\
\hline & \multicolumn{2}{|c|}{ Pre-treatment } & \multicolumn{2}{|c|}{ Post-treatment } & \multirow{2}{*}{$\dagger$} & \multirow{2}{*}{$\mathrm{p}$} \\
\hline & Mean & SD & Mean & SD & & \\
\hline CGI-S & 5.4 & 0.8 & 4.0 & 1.0 & 9.54 & $<0.001$ \\
\hline \multicolumn{7}{|l|}{ ADHD Rating Scale } \\
\hline Inattention & 17.4 & 4.2 & 11.7 & 4.5 & 8.62 & $<0.001$ \\
\hline Hyperactivity-impulsivity & 13.3 & 5.5 & 8.1 & 4.7 & 6.46 & $<0.001$ \\
\hline \multicolumn{7}{|l|}{ Advanced Test of Attention } \\
\hline \multicolumn{7}{|l|}{ Visual } \\
\hline Omission errors & 4.0 & 4.0 & 3.8 & 6.1 & 0.20 & 0.843 \\
\hline Commission errors & 3.5 & 3.0 & 3.5 & 4.4 & 0.05 & 0.961 \\
\hline Response time & 0.8 & 1.4 & 0.6 & 2.1 & 0.57 & 0.575 \\
\hline Response time variability & 2.6 & 2.4 & 2.1 & 2.8 & 1.16 & 0.252 \\
\hline \multicolumn{7}{|l|}{ Auditory } \\
\hline Omission errors & 1.8 & 2.5 & 2.0 & 4.4 & -0.49 & 0.627 \\
\hline Commission errors & 2.0 & 2.6 & 1.3 & 2.4 & 2.33 & 0.025 \\
\hline Response time & -0.5 & 1.2 & -0.6 & 1.7 & 0.58 & 0.568 \\
\hline Response time variability & 0.0 & 0.9 & -0.3 & 1.7 & 1.16 & 0.252 \\
\hline \multicolumn{7}{|l|}{$D C D Q$} \\
\hline Control during movement & 21.5 & 5.1 & 21.4 & 5.4 & 0.34 & 0.737 \\
\hline Fine motor/hand writing & 13.7 & 3.8 & 14.7 & 3.1 & -3.00 & 0.005 \\
\hline General coordination & 15.5 & 3.9 & 16.1 & 4.1 & -1.17 & 0.249 \\
\hline Total & 50.4 & 11.1 & 52.2 & 11.4 & -1.64 & 0.110 \\
\hline
\end{tabular}

ADHD: attention-deficit hyperactivity disorder, CGI-S: Clinical Global Impression-Severity Scale, DCDQ: Developmental Coordination Disorder Questionnaire, SD: standard deviation 
전후 통계적으로 유의하게 감소하였으며, 다중비교를 보정할 경우에도 통계적으로 유의하였다. ATA의 하위지표에서는 청 각 오경보 오류 $(\mathrm{p}=0.025)$ 가 유의하게 감소하였으며, 이외의 지 표에서는 치료 전후에 유의한 변화가 관찰되지 않았다. 하지 만 다중비교 보정 이후에는 청각 오경보 오류의 통계적 유의 성 또한 사라졌다.

$\mathrm{DCDQ}$ 의 경우 fine motor/hand writing 소척도 $(\mathrm{p}=0.005)$ 에 서 치료 전후로 점수가 유의하게 증가했다. 다중비교를 보정한 후에도 그 통계적 유의성은 유지되었다. 이외 control during movement 소척도, general coordination 소척도와 총점 모두 에서는 치료 전후 유의한 변화가 관찰되지 않았다.

\section{$\mathrm{DCD}$ 의심군과 비의심군에서의 치료 전후 $\mathrm{DCDQ}$ 결과 비교}

(Table 3)

$\mathrm{DCDQ}$ 결과에 따라 연구대상자를 $\mathrm{DCD}$ 의심군(n=23)과 비 의심군 $(\mathrm{n}=16)$ 으로 분류하고 이들 그룹 간 치료 전후 $\mathrm{DCDQ}$ 값 을 비교한 결과, fine motor/hand writing 소척도 $(\mathrm{p}=0.010)$ 는 시간에 대한 주효과가 유의했으나, 이외의 모든 소척도 및 총 점은 시간에 대한 주효과가 유의하지 않았다. 또한 그룹에 대한 주효과는 control during movement 소척도( $\mathrm{p}<0.001)$, fine motor/hand writing 소척도 $(\mathrm{p}<0.001)$, general coordination $(\mathrm{p}<0.001)$ 소척도 및 총점 $(\mathrm{p}<0.001)$ 모두에서 유의하였다. fine motor/hand writing 소척도가 유일하게 시간과 그룹 간 의 상호작용 효과가 유의하였고 $(\mathrm{p}=0.038)$, 이외의 소척도 및 총 점은 시간과 그룹 간의 상호작용 효과가 유의하지 않았다.

\section{치료 전후 $\mathrm{DCDQ}$ 점수 변화와 치료 전 $\mathrm{ADHD}$ 증상 간의 상관관계(Table 4)}

치료 전후 $\mathrm{DCDQ}$ 의 총점 변화량은 $\mathrm{ATA}$ 의 시각 오경보 오류 $(\mathrm{r}=0.330, \mathrm{p}=0.040)$ 와 양의 상관관계를 보였다. 이외에는 유의한 상관관계가 관찰되지 않았다.

\section{메칠페니데이트 그룹과 아토목세틴 그룹 간의 비교}

사용한 약물에 따라 그룹을 나누어 비교하였을 때 증상이 처음 시작된 연령(age of onset, $\mathrm{p}=0.023$ )과 연구 참여 당시의 연 령 $(\mathrm{p}=0.047)$ 에서 유의한 차이가 관찰되었으나, 그 이외의 인구 학적 요인과 임상증상에서의 차이는 없었다. 그룹 간 치료 전후 $\mathrm{DCDQ}$ 값을 비교한 결과, 시간에 대한 주효과는 fine motor/ hand writing 소척도 $(\mathrm{p}=0.005)$ 에서 유의하였으나 이외의 모 든 소척도 및 총점에서는 유의하지 않았다. 그룹에 대한 주효 과 및 시간과 그룹 간의 상호작용 효과는 모든 소척도 및 총점 에서 유의하지 않았다. 
Table 4. Correlation coefficients between DCDQ changes and pre-treatment ADHD related measures

\begin{tabular}{|c|c|c|c|c|c|c|c|c|c|c|c|c|}
\hline \multirow{3}{*}{ DCDQ changes } & \multirow{3}{*}{ CGI-S } & \multicolumn{3}{|c|}{ ADHD Rating Scale } & \multicolumn{8}{|c|}{ Advanced of Test of Attention } \\
\hline & & \multirow{2}{*}{ I } & \multirow{2}{*}{$\mathrm{HI}$} & \multirow{2}{*}{ Total } & \multicolumn{4}{|c|}{ Visual } & \multicolumn{4}{|c|}{ Auditory } \\
\hline & & & & & OME & CME & RT & RTV & OME & CME & RT & RTV \\
\hline Control during movement & 0.021 & -0.115 & 0.212 & 0.080 & 0.203 & 0.296 & -0.126 & 0.182 & -0.062 & 0.070 & -0.103 & 0.036 \\
\hline Fine motor/hand writing & -0.135 & -0.206 & 0.034 & -0.080 & 0.238 & 0.251 & 0.111 & 0.209 & 0.077 & 0.134 & -0.069 & 0.211 \\
\hline General coordination & 0.157 & -0.021 & 0.139 & 0.079 & 0.205 & 0.193 & -0.056 & 0.156 & -0.042 & 0.082 & -0.164 & 0.178 \\
\hline Total & 0.027 & -0.172 & 0.170 & 0.025 & 0.270 & $0.330 *$ & -0.058 & 0.223 & -0.052 & 0.135 & -0.154 & 0.200 \\
\hline
\end{tabular}

Change was calculated by subtracting from post-treatment measurement to pre-treatment measurement. ${ }^{*} p<0.05$. ADHD: attention-deficit hyperactivity disorder, CGI-S: Clinical Global Impression-Severity Scale, CME: commission errors, DCDQ: Developmental Coordination Disorder Questionnaire, HI: hyperactivity-impulsivity, I: inattention, OME: omission errors, RT: response time, RTV: response time variability

\section{비약물적 치료 시행 그룹과 미시행 그룹 간의 비교}

약물치료와 더불어 비약물적 치료를 시행한 아동과 그렇지 않은 아동 간의 치료 전후 $\mathrm{ADHD}$ 임상평가척도(CGI-S, ARS), $\mathrm{DCDQ}$ 결과값을 비교하였을 때 통계적으로 유의한 차이는 없었다. 또한 비약물적 치료 유무를 공변수로 하여 DCD 의심 군과 비의심군의 치료 전후 $\mathrm{DCDQ}$ 결과값을 비교해 보았을 때에도 두 군 간의 유의한 차이는 관찰되지 않았다.

\section{고 찰}

본 연구에서는 $\mathrm{ADHD}$ 약물치료 전후의 운동협응력을 비교 하여 $\mathrm{ADHD}$ 약물치료가 $\mathrm{ADHD}$ 아동의 운동협응력에 미치는 효과를 확인하였다. ADHD 아동에서 약물치료를 시행한 후, DCDQ 내 fine motor/hand writing 소척도 영역의 유의한 호 전이 관찰되었다. 전체 $\mathrm{ADHD}$ 아동을 $\mathrm{DCD}$ 의심군과 비의심 군으로 나누어 $\mathrm{DCDQ}$ 의 치료 전후 점수변화를 비교했을 때에 는, fine motor/hand writing 소척도에서 치료 전후 점수 변화 량이 $\mathrm{DCD}$ 의심군에서 더 컸다. 또한 치료 전후 $\mathrm{DCDQ}$ 총점 변화량과 치료 전 $\mathrm{ATA}$ 의 시각 오경보 오류가 유의한 상관관 계를 나타냈다.

본 연구에서는 DCDQ 내 fine motor/hand writing 소척도 영역이 약물치료 전후에 유의한 변화를 보였다. 이는 기존 연 구들에서 제시된 결과들과 일치한다. ${ }^{14,25} \mathrm{Kaiser}$ 등 25$)$ 은 $\mathrm{ADHD}$ 약물치료 후 대근육 운동능력의 변화는 없으나 소근육 운동 능력의 유의한 호전을 보여 소근육 운동이 약물치료에 좀 더 민감할 가능성을 제시하였다. 또한 Flapper 등는 $\mathrm{DCD}$ 를 공 존질환으로 가지는 $\mathrm{ADHD}$ 아동에서 약물치료가 글씨쓰기와 같은 소근육 운동의 호전에 특히 효과적일 가능성에 대해 언 급한 바 있다.

또한 본 연구에서는 $\mathrm{DCDQ}$ 에 의해 선별된 $\mathrm{DCD}$ 의심군이 비 의심군에 비해 $\mathrm{DCDQ}$ 내 fine motor/hand writing 소척도의 점수 변화량이 유의하게 컸다. 이는 운동결핍이 없는 $\mathrm{ADHD}$ 아동과는 달리, 운동결핍이 있는 $\mathrm{ADHD}$ 아동에서는 중추신
경자극제 치료 후 통계적으로 유의하게 운동결핍의 정도가 호 전됨을 관찰한 Brossard-Racine 등이의 연구와 일치하는 소 견이다.

본 연구에서는 치료 전후 $\mathrm{DCDQ}$ 총점 변화량과 치료 전 $\mathrm{ATA}$ 의 시각 오경보 오류가 유의한 양의 상관관계를 보였다. 이 는 치료 전 $\mathrm{ATA}$ 의 시각 오경보 오류가 치료 전후 $\mathrm{ADHD}$ 아동 에서 관찰되는 운동협응력 변화와 연관될 가능성을 시사한다. $\mathrm{ATA}$ 의 시각 오경보 오류는 반응억제(response inhibition)와 관련되었다고 알려져 있는데, ${ }^{26)} \mathrm{DCD}$ 아동의 반응억제 저하는 기존 연구들에서도 다수 보고된 바 있다. ${ }^{27,28)} \mathrm{ADHD}$ 와 $\mathrm{DCD}$ 를 동시에 가진 아동을 대상으로, 메칠페니데이트 복용 전후 의 운동기능 수준 및 주의력 관련 활동 수준을 평가하고 그 결과를 비교한 연구에서는 메칠페니데이트 복용 전후 운동협 응력 변화량과 연속수행력검사의 누락 오류 및 오경보 오류 변화량 간에 유의한 상관관계를 확인하였으나, 상호작용의 정 확한 메커니즘은 밝혀지지 않았다고 보고하였다. ${ }^{29}$

본 연구에서는 $\mathrm{ADHD}$ 아동에서 약물치료가 운동협응력을 일부 향상시킴을 확인하였다. 하지만 약물치료 전 $\mathrm{DCDQ}$ 에서 $\mathrm{DCD}$ 의심군이었던 아동의 $78.2 \%$ 는 3 개월의 약물치료 후에도 여전히 $\mathrm{DCD}$ 의심군으로 분류될 정도로 운동협응력 저하가 남아있었다. 이는 기존연구 결과와 일치하며, ${ }^{14)}$ 운동협응력 저 하가 뚜렷한 $\mathrm{ADHD}$ 아동에서는 약물치료 외에 운동협응력 향 상을 위한 추가적인 치료가 필요하다는 점을 시사한다. 이들에 게 시행하는 추가적 치료로는 감각통합치료, Cognitive-Orientation to Occupational Performance(CO-OP) 중재 등의 작업치료와 Neuromotor Task Training(NTT) 등의 물리치료 가 있다. ${ }^{10}$

대부분의 기존 연구들 ${ }^{14,16,25,29)}$ 은 ADHD 아동에서 메칠페니 데이트 약물치료 전후 일어난 운동협응력의 변화를 확인하였 다. 본 연구에는 메칠페니데이트 또는 아토목세틴 약물치료를 각각 시행한 아동들이 모두 포함되어 있다. 뿐만 아니라 전체 연구대상자 중 아토목세틴 약물치료를 시행한 아동이 약 $3 / 4$ $(\mathrm{n}=29,74.4 \%)$ 에 달해, 아토목세틴 약물치료 전후 일어난 운 
동협응력의 변화를 가늠할 수 있는 희소한 자료를 제공하고 있다. 본 연구의 결과는 임상적으로 아토목세틴 또한 $\mathrm{ADHD}$ 아동의 운동협응력 향상에 유의하게 기여할 수 있으며, 운동 협응력 향상 효과나 특성에서도 메칠페니데이트와 크게 차이 나지 않을 수 있음을 시사한다. 하지만, 이를 보다 정확히 확 인하기 위해서는 연구대상자 수가 충분히 확보된 메칠페니데 이트 치료군과 아토목세틴 치료군 각각에서의 치료 전후 운동 협응력의 변화를 확인하고, 그 차이를 비교분석하는 후속연 구가 필요하겠다. 또한 임상적인 효과와는 별도로 메칠페니데 이트와 아토목세틴이 운동협응력에 영향을 끼치는 기전은 다 를 것으로 예상된다. 일례로 $\mathrm{ADHD}$ 아동의 운동협응력과 연 관되어 있다고 알려진 생리적 표지자 transcranial magnetic stimulation-short interval cortical inhibition ${ }^{30}$ 은 메칠페니데 이트 약물치료 전후에 그 값이 증가하는데 반해, ${ }^{31)}$ 아토목세틴 약물치료 전후에는 운동협응력이 향상되더라도 그 값은 감소 함이 보고되기도 하였다. ${ }^{32)}$ 메칠페니데이트와 아모톡세틴, 각 각의 약물이 $\mathrm{ADHD}$ 아동의 운동협응력에 영향을 끼치는 기 전에 대해서 추가적인 연구가 필요하겠다.

본 연구에는 다음과 같은 제한점이 있다. 첫째, 본 연구는 개 방연구로 진행되어 이중 눈가림 연구와는 달리 연구진과 보호 자가 약물치료를 평가하는데 영향을 끼쳤을 가능성이 있다. 둘 째, 운동협응력 수준을 평가하는데 사용된 $\mathrm{DCDQ}$ 가 국내에 서 표준화 작업이 완전히 이루어지지 않았다. 셋째, $\mathrm{DCDQ}$ 외 에 연구대상자의 운동능력을 측정하는 객관적 도구가 포함되 지 않았다. 넷째, 메칠페니데이트와 아토목세틴으로 치료받은 아동을 함께 연구에 포함시켜 단일 제재에 의한 치료결과를 확인하기 어려웠다. 더불어 현재까지 아토목세틴이 $\mathrm{ADHD}$ 아 동의 운동협응력에 끼치는 영향에 대한 연구결과는 국내뿐 아니라 전세계적으로도 거의 없어 향후 연구대상자 수를 늘 려 아토목세틴 단독으로 운동협응력에 끼치는 영향을 확인하 는 연구를 진행하는 것이 필요하다고 판단된다. 또한 $\mathrm{ADHD}$ 와 운동협응력 간의 관계에 대한 연구도 필요하겠다. 다섯째, 잠재적으로 운동협응력에 영향을 끼칠 가능성이 있는 비약 물적 치료를 통제하지 않았다.

\section{결 론}

본 연구의 결과는 $\mathrm{ADHD}$ 의 약물치료가 $\mathrm{ADHD}$ 의 핵심 증상 뿐만 아니라 운동협응력 호전에도 도움이 될 수 있다는 근거를 제공한다. 본 연구를 바탕으로 $\mathrm{ADHD}$ 의 약물치료가 운동협응 력에 끼치는 영향에 대한 추후 연구가 필요하다.
중심 단어: 소아; 주의력결핍 과잉행동장애; 약물치료; 발달성 협응.

\section{Acknowledgments}

이 논문은 2015년도 정부(미래창조과학부)의 재원으로 한국연구재 단의 지원을 받아 수행된 기초연구사업임(No.2015R1A1A3A04001349).

\section{Conflicts of Interest}

The authors have no financial conflicts of interest.

\section{REFERENCES}

1) Barkley RA. Attentio-Deficit Hyperactivity Disorder: A Handbook for Diagnosis and Treatment. 3rd ed. New York, NY: Guilford Press; 2006. p.248-296.

2) American Psychiatric Association. Diagnostic and Statistical Manual of Mental Disorders (DSM-5). Arlington, VA: American Psychiatric Association;2013.

3) Tseng MH, Henderson A, Chow SM, Yao G. Relationship between motor proficiency, attention, impulse, and activity in children with ADHD. Dev Med Child Neurol 2004;46:381-388.

4) Adi-Japha E, Landau YE, Frenkel L, Teicher M, Gross-Tsur V, Shalev RS. ADHD and dysgraphia: underlying mechanisms. Cortex 2007; 43:700-709.

5) Cairney J, Veldhuizen S, Szatmari P. Motor coordination and emotional-behavioral problems in children. Curr Opin Psychiatry 2010; 23:324-329.

6) Skinner RA, Piek JP. Psychosocial implications of poor motor coordination in children and adolescents. Hum Mov Sci 2001;20:7394.

7) Goulardins JB, Rigoli D, Licari M, Piek JP, Hasue RH, Oosterlaan J, et al. Attention deficit hyperactivity disorder and developmental coordination disorder: two separate disorders or do they share a common etiology. Behav Brain Res 2015;292:484-492.

8) Song YJ, Joung YS. Clinical characteristics in attention-deficit hyperactivity disorder with/or without developmental coordination disorder patients. J Korean Acad Child Adolesc Psychiatry 2011;22: 307-313.

9) Rasmussen P, Gillberg C. Natural outcome of ADHD with developmental coordination disorder at age 22 years: a controlled, longitudinal, community-based study. J Am Acad Child Adolesc Psychiatry 2000;39:1424-1431.

10) Blank R, Smits-Engelsman B, Polatajko H, Wilson P. European Academy for Childhood Disability (EACD): recommendations on the definition, diagnosis and intervention of developmental coordination disorder (long version). Dev Med Child Neurol 2012;54: 54-93.

11) Martin A, Volkmar FR. Lewis's child and adolescent psychiatry: a comprehensive textbook. 4th ed. Philadelphia, PA: Lippincott Williams \& Wilkins;2007.

12) Jacobi-Polishook T, Shorer Z, Melzer I. The effect of methylphenidate on postural stability under single and dual task conditions in children with attention deficit hyperactivity disorder - a double blind randomized control trial. J Neurol Sci 2009;280:15-21.

13) Leitner Y, Barak R, Giladi N, Peretz C, Eshel R, Gruendlinger L, et al. Gait in attention deficit hyperactivity disorder: effects of methylphenidate and dual tasking. J Neurol 2007;254:1330-1338.

14) Flapper BC, Houwen S, Schoemaker MM. Fine motor skills and effects of methylphenidate in children with attention-deficit-hyperactivity disorder and developmental coordination disorder. Dev Med Child Neurol 2006;48:165-169.

15) Flapper BC, Schoemaker MM. Effects of methylphenidate on quality of life in children with both developmental coordination disorder and ADHD. Dev Med Child Neurol 2008;50:294-299. 
16) Brossard-Racine M, Shevell M, Snider L, Bélanger SA, Majnemer A. Motor skills of children newly diagnosed with attention deficit hyperactivity disorder prior to and following treatment with stimulant medication. Res Dev Disabil 2012;33:2080-2087.

17) Kaufman J, Birmaher B, Brent D, Rao U, Flynn C, Moreci P, et al. Schedule for affective disorders and schizophrenia for school-age children-present and lifetime version (K-SADS-PL): initial reliability and validity data. J Am Acad Child Adolesc Psychiatry 1997;36: 980-988.

18) Kim YS, Cheon KA, Kim BN, Chang SA, Yoo HJ, Kim JW, et al. The reliability and validity of kiddie-schedule for affective disorders and schizophrenia-present and lifetime version-Korean version (K-SADS-PL-K). Yonsei Med J 2004;45:81-89.

19) Wilson BN, Kaplan BJ, Crawford SG, Campbell A, Dewey D. Reliability and validity of a parent questionnaire on childhood motor skills. Am J Occup Ther 2000;54:484-493.

20) Wilson BN, Crawford SG, Green D, Roberts G, Aylott A, Kaplan BJ. Psychometric properties of the revised Developmental Coordina tion Disorder Questionnaire. Phys Occup Ther Pediatr 2009;29:182202.

21) DuPaul GJ. Parent and teacher ratings of ADHD symptoms: psychometric properties in a community-based sample. J Clin Child Psychol 1991;20:245-253.

22) So YK, Noh JS, Kim YS, Ko SG, Koh YJ. The reliability and validity of Korean parent and teacher ADHD Rating Scale. J Korean Neuropsychiatr Assoc 2002;41:283-289.

23) Shin MS, Cho S, Chun SY, Hong KE. A study of the development and standardization of ADHD diagnostic system. Korean J Child Adol Psychiatr 2000;11:91-99.

24) Guy W. Clinical Global Impressions. In: Guy W, editor. ECDEU assessment manual for psychopharmacology-revised. Rockville, MD:
US Department of Health, Education, and Welfare;1976. p.217-222.

25) Kaiser ML, Schoemaker MM, Albaret JM, Geuze RH. What is the evidence of impaired motor skills and motor control among children with attention deficit hyperactivity disorder (ADHD)? Systematic review of the literature. Res Dev Disabil 2014;36C:338-357.

26) Nigg JT, Stavro G, Ettenhofer M, Hambrick DZ, Miller T, Henderson JM. Executive functions and ADHD in adults: evidence for selective effects on ADHD symptom domains. J Abnorm Psychol 2005; 114:706-717.

27) Mandich A, Buckolz E, Polatajko H. On the ability of children with developmental coordination disorder (DCD) to inhibit response initiation: the simon effect. Brain Cogn 2002;50:150-162.

28) Michel E, Roethlisberger M, Neuenschwander R, Roebers CM. Development of cognitive skills in children with motor coordination impairments at 12-month follow-up. Child Neuropsychol 2011;17: 151-172.

29) Bart O, Daniel L, Dan O, Bar-Haim Y. Influence of methylphenidate on motor performance and attention in children with developmental coordination disorder and attention deficit hyperactive disorder. Res Dev Disabil 2013;34:1922-1927.

30) Gilbert DL, Isaacs KM, Augusta M, Macneil LK, Mostofsky SH. Motor cortex inhibition: a marker of ADHD behavior and motor development in children. Neurology 2011;76:615-621.

31) Buchmann J, Gierow W, Weber S, Hoeppner J, Klauer T, Benecke $\mathbf{R}$, et al. Restoration of disturbed intracortical motor inhibition and facilitation in attention deficit hyperactivity disorder children by methylphenidate. Biol Psychiatry 2007;62:963-969.

32) Chen TH, Wu SW, Welge JA, Dixon SG, Shahana N, Huddleston DA, et al. Reduced short interval cortical inhibition correlates with atomoxetine response in children with attention-deficit hyperactivity disorder (ADHD). J Child Neurol 2014;29:1672-1679. 